\title{
A REVIEW: AIR POLLUTION MONITORING SYSTEM USING IOT
}

\author{
Anuradha S Dige \\ M. Tech. Student \\ Department of CSE \\ M. S. Bidve Engineering College, Latur, Maharashtra, \\ India
}

\begin{abstract}
Internet of Things (IoT) may be a worldwide system of "smart devices" which will sense and connect with their surroundings and interact with users and other systems. Global pollution is one among the main concerns of our era. Existing monitoring systems have inferior precision, low sensitivity, and need laboratory analysis. Therefore, improved monitoring systems are needed. To overcome the issues of existing systems, we propose a three-phase pollution monitoring system. An IoT kit was prepared using some sensors, Arduino IDE (Integrated Development Environment), and a Wi-Fi module. This kit is often physically placed in various cities to monitoring pollution. The sensors gather data from air and forward the data to the Arduino IDE. The Arduino IDE transmits the info to the cloud via the Wi-Fi module. It can be monitored from android mobile phone also. The proposed system is predicting the quality of air using different sensors and stored data in database and cloud so any one can retrieve data from anywhere anytime. Furthermore, air quality data are often wont to predict future air quality index $(A Q I)$ levels.
\end{abstract}

Keywords- AQI, IDE, IoT, PM.

\section{INTRODUCTION}

Air contamination has been a gigantic worry in nowadays. It became necessary to monitor air pollution and to keep it well within the limits for a better future and healthy living. Air contaminations cause different medical problems. Among this, $\mathrm{CO}$, which is a result of fragmented ignition of fills, is the significant benefactor. Vehicular fumes is a significant wellspring of $\mathrm{CO}$. The wellbeing risk because of steady presentation to $\mathrm{CO}$ is generally genuine, for the individuals who experience the ill effects of cardiovascular ailment. Particulates, then again called as environmental particulate issue (PM), or fine particles, are modest particles of strong or fluid suspended in a gas. Expanded degrees of fine particles noticeable all around are connected to wellbeing perils, for example, coronary illness, change lung capacity and causes lung disease. Air contamination is liable for some medical issues in the urban territories. Generally, the air contamination status in Delhi has experienced numerous adjustments as far as

\author{
Shrikant R Tandle \\ Assistant Professor \\ Department of CSE \\ M. S. Bidve Engineering College, Latur, Maharashtra, \\ India
}

the degrees of poisons and the control estimates taken to lessen them. It was evaluated that 3000 metric huge amounts of air toxins were transmitted each day in Delhi, with a significant commitment from vehicular contamination (67\%), trailed by coal-based warm power plants $(12 \%)$. There was a rising pattern in contamination as checked by the Central Pollution Control Board (CPCB). The system comprises of 621 working stations covering 262 urban communities/towns in 29 states and 5 Union Territories of the nation. There are state contamination control sheets (SPCBs), guided and actually helped by CPCB. The Kerala State Pollution Control Board is an assemblage of under Department of Health and Family Welfare. The board is resolved to give contamination free condition to the individuals of state. In any case, right now their checking limits too hardly any locales, which is a significant disadvantage [4].

\section{PARAMETERS AFFECTING ENVIRONMENT}

By the ever-growing awareness of GREEN EARTH since last few decades, it has been brought to the notice that human activities are mainly responsible for all kind of air pollutions. Apart from industrial and automobile pollution, the big buildings are also having a largest SHARE OF PIE in polluting the environment and consumption [3]. India being a developing nation and therefore the energy required for economic process is imported in majority; things here is under great distress because of quite increasing pollution on day to day basis [9].

\section{NEED OF MONITORING AIR POLLUTION}

Clean air is fundamental requirement for each individual. Polluted air causes numerous medical issues and a few harms. Along these lines to make any progression in front of controlling the contamination rate it is important to monitor the air quality which may assist us with making a correct choice at perfect time. There are different reasons for expanding the contamination, for example, smoke car fumes, concoction release from enterprises, radioactive substance and so forth. These are principle reason of diminishing the nature of air. The primary gases which straightforwardly influence the human wellbeing are carbon monoxide (CO), hydrogen sulfide, sulfur dioxide (SO2), Nitrogendioxide (NO2) and the 
fundamental commitment of these gases are traffic related toxin emanation. Enormous endeavors are required to improve the nature of air in both outside and indoor condition. Checking of condition has been controlled from manual to the programmed control bit by bit. There are different improvement in the instrument of condition checking yet at the same time can't meet the brutal condition [2].

\section{LITERATURE REVIEW}

\section{Technique used for pollution monitoring}

Previously the pollution monitoring is completed via computed tomography technique which generate a twodimensional map of pollutant concentration. It provides a many advantage over the differential absorption method. In this system there is a single laser source located at the center of the area. This beam is rotated and directed towards the circumference of the circle. There is a cylindrical mirror in order that incident beam is reflected during a fan beam over angle across the circle. The beam from the mirrors is that the circular region and strikes a group of detectors consist same plane parallel to the bottom. This technique specialize in lower transmitted laser energy increasing the range and skill to watch the world that contains several pollutant sources [3]. Another way of monitoring the air pollution is via the online GPRS sensors array which has been designed, implemented and tested. This system unit that consists at one chip of microcontroller and a pollution server which may be a highend personal application server with a internet connectivity where the mobile data acquisition unit that collect the pollution level \& pack it into a frame with GPS location, date and time. This frame is uploaded to the GPRS modem and transmitted to the pollution server via the general public mobile network. A data base server which is attached to the pollution level which is employed by the varied client. Pollution server for storing the pollution level which is employed by the varied clients. Pollution server having a interfaced with the Google map to supply a true time pollutants level also because the location in large metropolitan area [4].

\section{Wireless sensor network for real time monitoring}

A distributed infrastructure consists of a wireless sensor network and grid computing technology for pollution monitoring also as mining. However, the 2 layer specification and peer to see e-science grid architecture and distributed data processing algorithms are utilized in order to gather the info and tiny operating system is used to examine the operation and performance of the wireless sensor network [7].Wireless sensor network is the great achievement in this field. An effective solution for the pollution monitoring using a wireless sensor network to provide a real time pollution data. The various gases like $\mathrm{CO} 2, \mathrm{NO} 2$ are calibrated by employing a appropriate calibration technologies and these recalibrated sensors are integrated with the wireless sensor employing a multi hop data aggregation algorithm. A light weight middleware and web interface so as to look at the one pollution data within the sort of charts and number. It is also available on the internet. The other parameters like temperature and humidity are also sensed along with the gas concentrations which enable the data analysis through the data fusion techniques this system provide accurate pollutant data [8]. The air quality monitoring system combines with the virtual instrument technology \& frequency hopping communication technology to realize the wireless data transmission. By employing a spectrum hole detection specimens that adjust a carrier frequency consistent with the result \& made a full use of obtainable radio-frequency spectrum with this specimen there is no signal interference during the wireless transmission process \& the system can receive the important time information effectively and therefore the gas concentration can show clearly and straightforward to read by the nonprofessional staff also [9]. The air quality monitoring station are wont to monitor the standard of air but most of this method are expensive and supply a coffee resolution sensing data and these stations are less densely deployed therefore the system contains sensor mode gateway and rear platform controlled by the lab view program through which the info are often stored in the database the system deployed to the most road within the city to watch the carbon monoxide gas concentration caused by the vehicle emission the benefits of those wireless sensor network is that it is easy to set up, inexpensive and also provide a real time data[10]. The system during which several monitoring stations communicate wirelessly with the backend server using machine to machine communication $\&$ each station equipped with the metro logical sensor and gaseous sensor for data logging and wireless communication capabilities. The backend server collects the real time data from station and converts it in to the information which is used by the user through the web portals and mobile application [11]. The small scale of wireless sensor station to communicate with the backend server and provide their measurement in a real time however the collected data are process and analyze in order to provide these data in different format to the end user [12].

\section{Centralized monitoring}

Different sensors are deploying to the different region and each sensor must send their collected information to server so that the end user can easily see the pollution information in the different area. Centralize monitoring make sure the quality, improve the power and integrity of knowledge. Collected data are uploaded to the cloud dataset in order that they are often analyze or viewed for future use. All these uploaded data are managed in database management system over the centralize database with this available information the user can search the record as per their requirement.

Pollution level monitor over the google map 


\section{International Journal of Engineering Applied Sciences and Technology, 2020 \\ Vol. 4, Issue 10, ISSN No. 2455-2143, Pages 159-162 \\ Published Online February 2020 in IJEAST (http://www.ijeast.com)}

The main objective of monitoring is to display the collected information in user friendly format. The mobile application and websites are developing in order to display the real time data that contains previous history and recent measurement of pollution level. Only the authorized user can access the website which is easily available to the public when the permission is granted. Website allows displaying the various level of pollution in several area over the Google map. With the help of internet connectivity, it is possible to display the different level of pollution at different area on the Google map [13].

\section{Types of sensor}

There are differing kinds of sensors are available for collecting the atmospherically data. Such as Temperature sensor, Humidity sensor, Rain sensor, Gas Sensor etc... Different types of gas sensors are available to collect the different gases from the road traffic emission such as $\mathrm{CO} 2$ sensor, $\mathrm{NO} 2$ sensor, $\mathrm{SO} 2$ sensor etc. Wireless sensor network built a node where each node is connected to at least one sensor. With the extra sensors may help to reinforce the network and monitoring the extra pollutants. With the assistance of sensors, it's going to possible to gather the environment related information. It is deployed in several cities to monitor the concentration of dangerous gases for citizen. Air quality measurement can process and presented during a real time to the top user during a friendly format to spread environmental awareness among the population and permit taking appropriate precaution when it is needed.

\section{PROBLEM DEFINATION}

A. Air pollution is a rising issue these days. It is necessary to monitor air quality and keep it under control for a better future and healthy living for all.

B. Here system propose an air pollution monitoring system that allows us to monitor and check live air quality as and pollution in particular areas.

\section{PROPOSED SYSTEM}

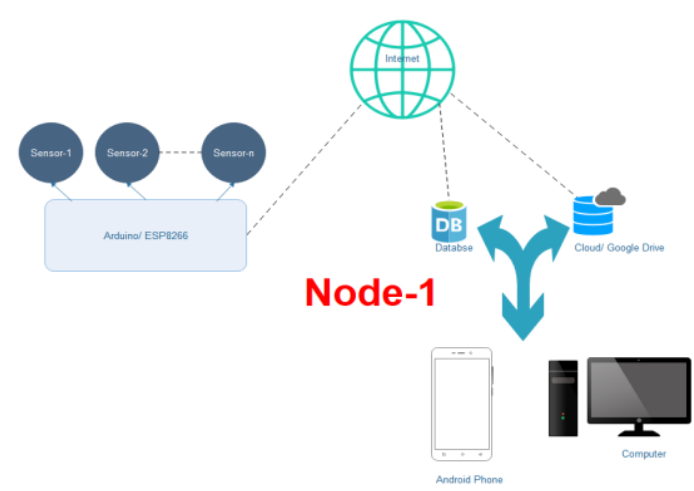

Figure 1 Node-1

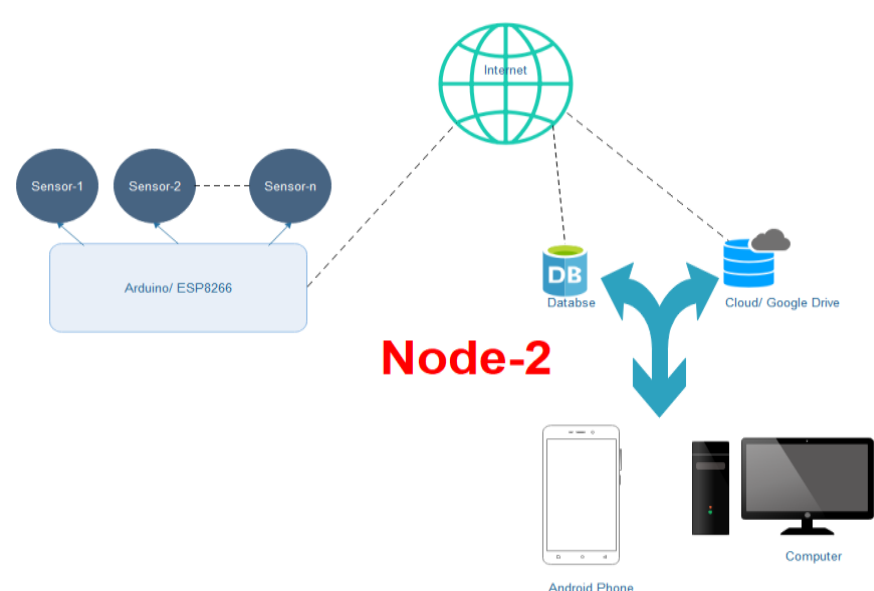

Figure 2 Node-2

Figure 1 shows the connection of different sensors with Arduino microcontroller, the Arduino is connected with Internet through WiFi module. The data received from sensor stored on Database as well as Cloud or Google Drive. The data can be displayed on computer and android mobile phone. The figure 2 also depicted the same but the result will be combined and shows as per the location where module placed.

\section{OBJECTIVE OF THIS STUDY AND PROPOSAL}

The pollution has numerous ill effects on citizenry also because the complete biological system on the world. Reducing all quite emissions that cause poor air quality and degrade the ambient environment around us requires teamwork. We try to develop a system which may detect all quite air pollutants and is more advantageous compare to other available systems as per the following table [8].

\begin{tabular}{|c|c|c|}
\hline Parameter & $\begin{array}{c}\text { Semiconductor } \\
\text { sensors }\end{array}$ & Other sensors \\
\hline Energy efficiency & $\begin{array}{c}\text { Power requirement } \\
\text { is low }\end{array}$ & $\begin{array}{c}\text { Power } \\
\text { requirement is } \\
\text { high }\end{array}$ \\
\hline cost & Less expensive & Expensive \\
\hline $\begin{array}{c}\text { Detection of } \\
\text { gases }\end{array}$ & $\begin{array}{c}\text { Detects variety of } \\
\text { gases }\end{array}$ & $\begin{array}{c}\text { Detects less } \\
\text { number of gases }\end{array}$ \\
\hline
\end{tabular}

\section{CONCLUSION}

The Proposed System proposes, an effective implementation for Internet of Things is used for monitoring atmospheric conditions of environment like air pollution. This paper presents a conceptual architecture for a flexible, flexible and price efficient for monitoring the air of a specific site. System propose an air quality monitoring system that allows us to monitor and check live air quality in an area through IOT. The air pollution monitoring system using various gas sensors senses the pollutant levels and uploads the data in web server or cloud, thus making the public get easy access to the 


\section{International Journal of Engineering Applied Sciences and Technology, 2020 \\ Vol. 4, Issue 10, ISSN No. 2455-2143, Pages 159-162 \\ Published Online February 2020 in IJEAST (http://www.ijeast.com)}

pollution level in their area. This is of wide use to offices, factories, residential areas and education institutions, if installed in their premises, because staying in tune with the changes in our environment is the most necessity of today

\section{ACKNOWLEDGMENT}

I would like to say thanks to Prof. Shrikant R. Tandle, for his kind support and valuable guidance. He has done B.E. (Electronics) from SGGS College of Engineering and Technology, Nanded and M.E.(Computer Science and Engineering ) from MGM College of Engineering, Nanded. $\mathrm{He}$ is working as Assistant Professor and Head of CSE Department in M. S. Bidve Engineering College, Latur since 1990. I will forever remain grateful for constant support and guidance extended by him, for the completion of paper.

\section{REFERENCE}

[1] Dhruvil Shah, Prathmesh Kudale, Prasad Shirwadkar, Samuel Jacob, 2018, Iot Based Air and Sound Pollution Supervising System, IOSR Journal of Engineering.

[2] Arushi Singh, Divya Pathak, Prachi Pandit, Shruti Patil, Prof. Priti . C. Golar, 2017, IOT based Air and Sound Pollution Monitoring System, International Journal of Advanced Research in Electrical, Electronics and Instrumentation Engineering.

[3] Ms. Sarika Deshmukh, Mr. Saurabh Surendran, Prof. M.P. Sardey, 2017, Air and Sound Pollution Monitoring System using IoT, International Journal on Recent and Innovation Trends in Computing and Communication,.

[4] Akhil Joseph, Amila Ikbal, Anitta V J, Arjun R Krishnan, Neema M, May 2018, "IoT enabled Air Quality Monitoring and Visualization System", National Conference on Recent Trends in VLSI, Communication and Networks 2018, ISSN: 2454-4248 81 - 84, Volume: 4 Issue: 5, IJFRCSCE , Available @ http://www.ijfrcsce.org (Special Issue).

[5] Dhanashri Ajay konnur, Dr. L K Ragha, July 2016, "Review Paper on Smart Sensor Network for Air Quality Monitoring", International Journal of Innovative Research in Advanced Engineering (IJIRAE) ISSN: 2349-2763, Issue 07, Volume 3.

[6] IEO international energy outlook, 2009, " Energy Information Administration, Washington, DC, Tech. Rep.

[7] Al-Ali, A. R.; Zualkernan, I.; Aloul, F. Oct. 2010, "A Mobile GPRS Sensors Array For Air Pollution Monitoring," Sensors Journal, IEEE, Vol.10, No.10, Pp.1666, 1671..

[8] Raja Vara Prasad Y1, Mirza Sami Baig2, Rahul K. Mishra3, P. Rajalakshmi4, U. B. Desai5 And S.N. Merchant,6 June 2011, "Real Time Wireless Air Pollution Monitoring System" Ictact Journal On Communication Technology: Special Issue On Next
Generation Wireless Networks And Applications, Volume -2 , Issue -2 .

[9] Haibao Wang, Tingting Wu , And Guangjie Wu, August 2010, "Air Quality Monitoring System Based On Frequency Hopping System" International Conference On Intelligent Control And Information Processing.

[10] Jen-Hao Liu, Yu-Fan Chen, Tzu-Shiang Lin, And Da-Wei Lai ,Tzai-Hung Wen, Chih-Hong Sun, And Jehn-Yih Juang,Joe 2011 -Air Jiang developed Urban Air Quality Monitoring System Based On Wireless Sensor Networks Ieee.

[11] Srinivas Devarakonda, Parveen Sevusu, Hongz Hang Liu, Ruilin Liu, Liviu Iftode, Badri Nath Urbcomp, August 2013 Acm " Real-Time Air Quality Monitoring Through Mobile Sensing In Metropolitan Areas ${ }^{\text {ee }} 13$.

[12] Fouzi Harrou, Mohamed Nounou,Hazem Nounou "Detecting Abnormal Ozone Levels Using Pca Based Glr Hypothesis Testing"2013 Ieee Symposium On Computational Intelligence And Data Mining.

[13] Elias Yaacoub,Abdullah Kadri,Mohammad Mushtaha,And Adman Abu-Dayya, 2013,'Air Quality Monitoring And Analysis In Qatar Using A Wireless Sensor Network Deployment"596-601, Ieee. 